\title{
A Silver(I) Iodide Complex of a Tellurophosphorane
}

\author{
Andreas Nordheider, ${ }^{[a][b]}$ Alexandra M. Z. Slawin, ${ }^{[b]}$ J. Derek Woollins ${ }^{[b]}$ and Tristram Chivers ${ }^{*[a]}$
}

Keywords: Silver; Phosphorus; Tellurium; Cyclodiphosphazane; Crystal structure

\begin{abstract}
The formation and structural characterization of the first coordination complex of the tellurophosphorane $[t \mathrm{Bu}(\mathrm{H}) \mathrm{NP}(\mu$ $\left.\mathrm{N} t \mathrm{Bu})_{2} \mathrm{P}(\mathrm{Te}) \mathrm{N}(\mathrm{H}) t \mathrm{Bu}\right]$ are presented. The silver(I) iodide complex $\left\{(\mathrm{I}) \mathrm{Ag}\left[t \mathrm{Bu}(\mathrm{H}) \mathrm{NP}(\mu-\mathrm{N} t \mathrm{Bu})_{2} \mathrm{P}(\mathrm{Te}) \mathrm{N}(\mathrm{H}) t \mathrm{Bu}\right]_{3}\right\}$ (2) was isolated from the reaction of $\left.[\mathrm{Li}(\mathrm{TMEDA})]_{2}\left[t \mathrm{BuN}(\mathrm{Te}) \mathrm{P}(\mu-\mathrm{N} t \mathrm{Bu})_{2} \mathrm{P}(\mathrm{Te}) \mathrm{N} t \mathrm{Bu}\right)\right]$ (1) with AgI in toluene and characterized by X-ray analysis and multinuclear NMR spectroscopy.
\end{abstract}

Complex $\mathbf{2}$ is comprised of three tellurophosphorane ligands coordinated to AgI in a distorted tetrahedral arrangement (102.90(3)-114.51(5) ${ }^{\circ}$ ). The $\mathrm{P}=\mathrm{Te}$ bond distances of 2.3883(13)-2.4043(17) $\AA$ in 2 are slightly elongated compared to those in the free ligand.
* Prof. Dr. Tristram Chivers Fax: 001-403-289-9488

E-Mail: chivers@ucalgary.ca

[a] Department of Chemistry

University of Calgary

Calgary, AB, Canada T2N 1N4

[b] EaStCHEM School of Chemistry

University of St Andrews

St Andrews, Fife, KY16 9ST, UK

\section{$\Xi$ Introduction}

Although trialkylphosphane

tellurides (tellurophosphoranes) $\mathrm{R}_{3} \mathrm{PTe}$ have been known since $1963,{ }^{[1]}$ examples of structurally characterized coordination complexes are scarce. Kuhn et al. reported the first stable complex, $\mathrm{M}(\mathrm{CO})_{5}\left(\mathrm{TeP} t \mathrm{Bu}_{3}\right)$, in 1985 and obtained the crystal structure of the chromium derivative. ${ }^{[2]}$ More recently, $d u$ Mont et al. were able to structurally characterize the first $\operatorname{Ag}(\mathrm{I})$ complexes of a trialkylphosphane telluride and showed that the tellurium-centered ligand may function in a bridging mode e.g. $\left[\left(\mathrm{Ms}_{2} \mathrm{~N}\right) \mathrm{Ag}\left(\mu-\mathrm{TeP} \mathrm{Pr}_{3}\right)\right]_{2}(\mathrm{Ms}=$ $\left.\mathrm{SO}_{2} \mathrm{CH}_{3}\right)$, as well as a terminal ligand in $\left[\mathrm{Ag}\left(\mathrm{TePiPr}_{3}\right)_{3}\right]\left[\left(\mathrm{NMs}_{2}\right] .{ }^{[3]}\right.$ However, silver(I) halide complexes had previously eluded characterization owing to facile decomposition. ${ }^{[4]}$

We have previously shown that the phosphorus-tellurium bond is stabilized by a negative charge in the anionic ligands $\left\{\left[\mathrm{R}_{2} \mathrm{P}(\mathrm{Te})\right]_{2} \mathrm{~N}\right\}^{-[5]}$ and we reported the X-ray structures of hexameric and tetrameric $\operatorname{Ag}(\mathrm{I})$ complexes of this ligand for $\mathrm{R}=i \mathrm{Pr}$ and $\mathrm{Ph}$, respectively. ${ }^{[6]}$ In a sequel to that work we have now investigated the reaction of the $\mathrm{P}-\mathrm{Te}$ dianion $\left.\left[t \mathrm{BuN}(\mathrm{Te}) \mathrm{P}(\mu-\mathrm{N} t \mathrm{Bu})_{2} \mathrm{P}(\mathrm{Te}) \mathrm{N} t \mathrm{Bu}\right)\right]^{2-}(\mathbf{A})^{[7]}$ with silver(I) iodide and found, unexpectedly, that a AgI complex of the neutral monotelluride $\left(\left[t \mathrm{Bu}(\mathrm{H}) \mathrm{N}(\mathrm{Te}) \mathrm{P}(\mu-\mathrm{N} t \mathrm{Bu})_{2} \mathrm{PN}(\mathrm{H}) t \mathrm{Bu}\right]\right)$ (B) ${ }^{[8]}$ is formed.

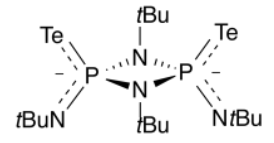

A

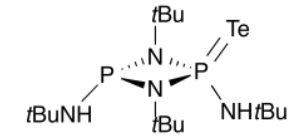

B
Scheme 1.

\section{Results and Discussion}

Treatment of the dilithium reagent $\left.[\mathrm{Li}(\mathrm{TMEDA})]_{2}\left[t \mathrm{BuN}(\mathrm{Te}) \mathrm{P}(\mu-\mathrm{N} t \mathrm{Bu})_{2} \mathrm{P}(\mathrm{Te}) \mathrm{N} t \mathrm{Bu}\right)\right]$ (1) with one equivalent of $\mathrm{AgI}$ produced the silver(I) complex $\left\{(\mathrm{I}) \mathrm{Ag}\left[t \mathrm{Bu}(\mathrm{H}) \mathrm{NP}(\mu-\mathrm{N} t \mathrm{Bu})_{2} \mathrm{P}(\mathrm{Te}) \mathrm{N}(\mathrm{H}) t \mathrm{Bu}\right]_{3}\right\}$ (2) in toluene at $-78{ }^{\circ} \mathrm{C}$ in low yield (14\%) (Scheme 2 ). The low yield is attributed to the 1:1 molar ratio of reactants (unreacted AgI was recovered) and partial decomposition (formation of elemental tellurium was observed). Presumably, hydrolysis generated the monoprotonated ligand $\mathbf{B}$.

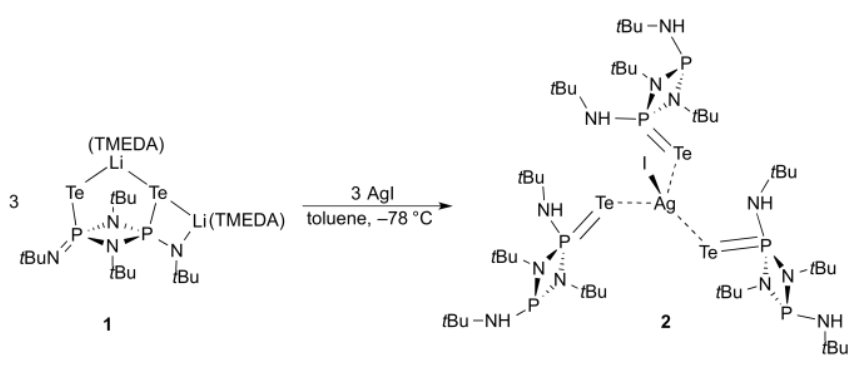

Scheme 2. Formation of $\{(\mathrm{I}) \mathrm{Ag}[t \mathrm{Bu}(\mathrm{H}) \mathrm{NP}(\mu-$ $\left.\left.\mathrm{N} t \mathrm{Bu})_{2} \mathrm{P}(\mathrm{Te}) \mathrm{N}(\mathrm{H}) t \mathrm{Bu}\right]_{3}\right\}(2)$.

The identity of $\mathbf{2}$ was established by single-crystal X-ray analysis. Colorless prism-shaped crystals were isolated after recrystallization from $n$-hexane at $-40{ }^{\circ} \mathrm{C}$. The molecular structure of $\mathbf{2}$ is depicted in Figure 1 along with selected structural parameters. Crystal data and structure refinement details are presented in Table 1.

Table 1. Crystal data and structure refinement for 2 .

\begin{tabular}{ll}
\hline & \multicolumn{1}{c}{$\mathbf{2}$} \\
\hline Formula & $\mathrm{C}_{49.75} \mathrm{H}_{118} \mathrm{AgIN}_{12} \mathrm{P}_{6} \mathrm{Te}_{3}$ \\
$\mathrm{M}_{\mathrm{r}}$ & 1687.98 \\
Crystal size $/ \mathrm{mm}$ & $0.20 \times 0.20 \times 0.10$ \\
Crystal system & monoclinic \\
Space group & $C 2 / c$ \\
$a / \AA$ & $52.821(11)$
\end{tabular}




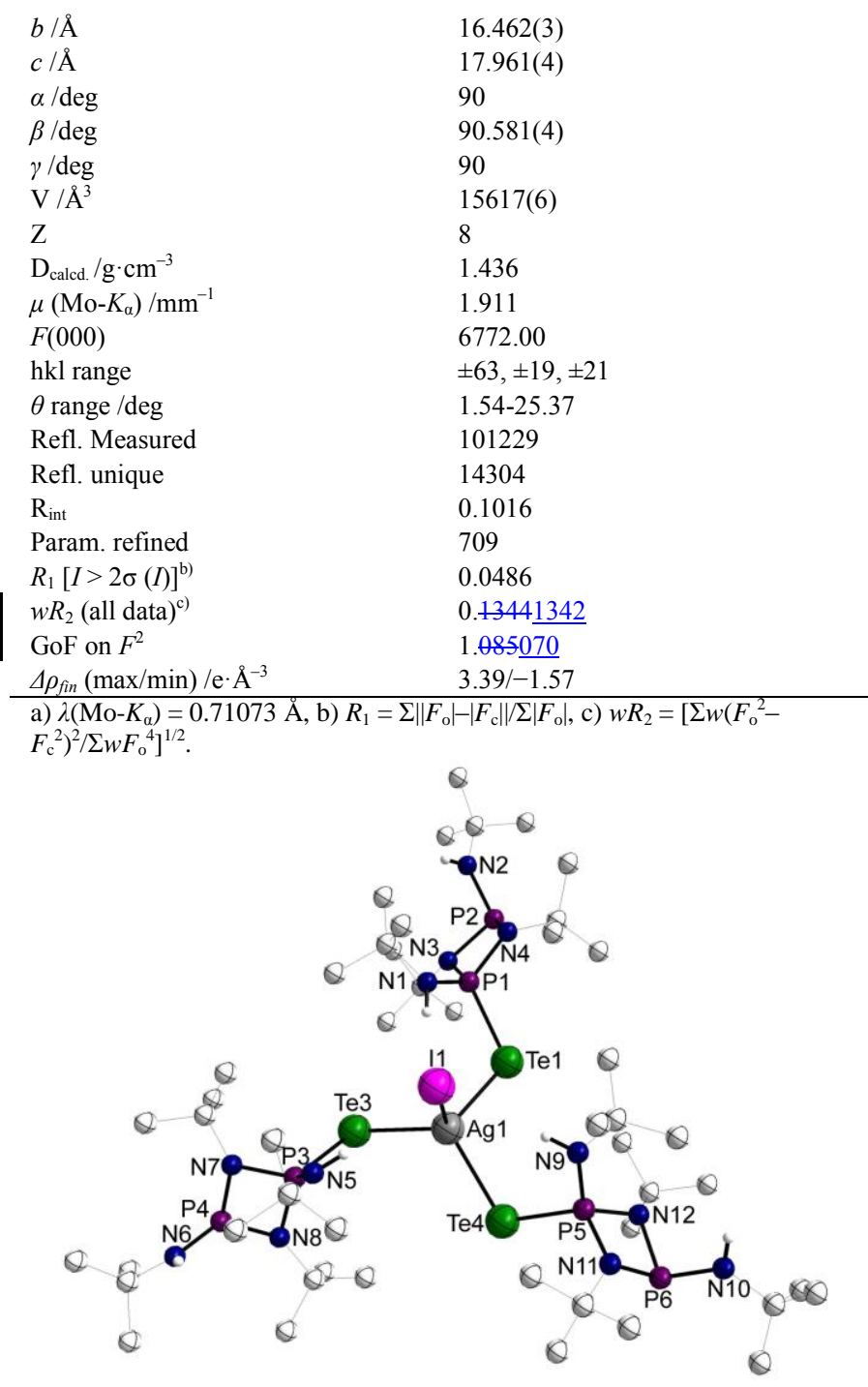

Figure 1. X-ray crystal structure of $\{(\mathrm{I}) \operatorname{Ag}[t \mathrm{Bu}(\mathrm{H}) \mathrm{NP}(\mu$ $\left.\left.\mathrm{N} t \mathrm{Bu})_{2} \mathrm{P}(\mathrm{Te}) \mathrm{N}(\mathrm{H}) t \mathrm{Bu}\right]_{3}\right\}(2)$. Hydrogen atoms bonded to $\mathrm{C}$ atoms and one $n$-hexane molecule omitted for clarity. Selected bond lengths $(\AA)$ and angles $\left({ }^{\circ}\right)$ : I1-Ag1 2.8504(9), Te1-Ag1 2.8236(8), Te1-P1 2.3883(13), Te3-Ag1 2.7906(12), Te3-P3 2.3930(13), Te4-Ag1 2.8114(11), Te4-P5 2.4043(17), P1-N1 1.635(4), P1-N3 1.688(4), P1-N4 1.682(4), P2-N2 1.666(4), P2-N3 1.758(4), P2N4 1.755(4); Ag1-Te1-P1 106.60(3), Ag1-Te3-P3 105.56(5), Ag1-Te4-P5 103.79(4), I1-Ag1-Te1 108.94(2), I1-Ag1-Te3 109.90(3), I1-Ag1-Te4 114.51(5), Te1-Ag1-Te3 106.61(4), Te1Ag1-Te4 102.92(2), Te3-Ag1-Te4 113.37(2), Te1-P1-N1 105.68(14), Te1-P1-N3 118.25(14), Te1-P1-N4 116.97(15), N1P1-N3 115.07(19), N1-P1-N4 116.6(2), N3-P1-N4 83.8(2), N2P2-N3 104.8(2), N2-P2-N4 105.0(2), N3-P2-N4 79.67(18).

Complex 2 is comprised of an $\mathrm{Ag}(\mathrm{I})$ center bonded to an iodide ion and coordinated to the tellurium atoms of three neutral ligands $\mathbf{B}$ via terminal $\mathrm{P}=\mathrm{Te}$ bonds. Although phosphane complexes of AgI are known, ${ }^{[9]}$ the preferential coordination of $\operatorname{Ag}(\mathrm{I})$ to the soft tellurium center rather than the P(III) donor site in $\mathbf{B}$ is expected. The geometry of $\mathbf{2}$ can best be described as a distorted tetrahedron with bond angles around the central Ag atom ranging from 102.92(2) ${ }^{\circ}$ to $114.51(5)^{\circ}$. By contrast, the ion-separated complex $\left[\mathrm{Ag}\left(\mathrm{TePiPr}_{3}\right)_{3}\right]^{+}\left[\left(\mathrm{SO}_{2} \mathrm{CH}_{3}\right)_{2} \mathrm{~N}\right]^{-}$, which has three phosphane telluride ligands coordinated to $\mathrm{Ag}^{+}$, exhibits a regular trigonal geometry. ${ }^{[3]}$

The Ag-Te distances in 2 range from 2.7906(12) to $2.8236(8) \AA$ and are significantly longer than the values of
2.6956(9)-2.7181(9) ^) reported for the terminal $i \mathrm{Pr}_{3} \mathrm{PTe}$ ligands in the dinuclear complex $\left.\left.\mathrm{Ag}_{2}\left(\mathrm{SO}_{2} \mathrm{CH}_{3}\right)_{2} \mathrm{~N}\right)\left(i \mathrm{Pr}_{3} \mathrm{PTe}\right)_{4}\right]\left[\left(\mathrm{SO}_{2} \mathrm{CH}_{3}\right)_{2} \mathrm{~N}\right] \cdot \mathrm{CH}_{3} \mathrm{CN}$ presumably due to the positive charge in the cation of the latter complex. ${ }^{[3]}$ The P-Te bond lengths of 2.388(1) - 2.404 (2) $\AA$ in $\mathbf{2}$ are only slightly elongated compared to the value of $2.370(1) \AA$ found for the neutral monotelluride ligand B. ${ }^{[7]}$ A similar elongation compared to the free ligand was observed for the P-Te distances in the $\mathrm{Ag}^{+}$complexes of $i \operatorname{Pr}_{3}$ PTe reported by $d u$ Mont et al. ${ }^{[3]}$

The ${ }^{31} \mathrm{P}$ NMR spectrum of $(2)$ at $25^{\circ} \mathrm{C}$ exhibits two broad resonances at 83.0 and $-46.0 \mathrm{ppm}\left[{ }^{1} J(\mathrm{P}, \mathrm{Te})=1939 \mathrm{~Hz}\right]$ attributed to the $\mathrm{P}(\mathrm{III})$ and $\mathrm{P}(\mathrm{V})$ centers, respectively, ( $c f$. ${ }^{1} J(\mathrm{P}, \mathrm{Te})=2024 \mathrm{~Hz}$ for $\left.\mathbf{B}\right) .^{[8]}$ The broad signals are presumably due to the existence of rapid exchange equilibria, which is known to occur for the $\mathrm{P}(\mathrm{III})$ and $\mathrm{P}(\mathrm{V})$ sites in the tellurophosphane $i \mathrm{Pr}_{2} \mathrm{PCH}_{2} \mathrm{P}(\mathrm{Te}){\mathrm{P} i \mathrm{Pr}_{2} \text {. }}^{[9]}$

\section{Conclusion}

The first coordination complex of the neutral tellurophosphorane ligand $\mathbf{B}$ was obtained as the silver iodide complex $\quad\left\{(\mathrm{I}) \mathrm{Ag}\left[t \mathrm{Bu}(\mathrm{H}) \mathrm{NP}\left(\mu^{-}\right.\right.\right.$ $\left.\left.\mathrm{N} t \mathrm{Bu})_{2} \mathrm{P}(\mathrm{Te}) \mathrm{N}(\mathrm{H}) t \mathrm{Bu}\right]_{3}\right\}$ (2) in which three molecules of $\mathbf{B}$ are coordinated to $\mathrm{AgI}$ in a distorted tetrahedral arrangement. The characterization of $\mathbf{2}$ is significant since the monotelluride $\mathbf{B}$ is only available in 5\% yield via telluration of the $\mathrm{P}(\mathrm{III}) / \mathrm{PIII}$ ) precursor and it decomposes readily in solution. ${ }^{[8]}$

\section{Experimental Section}

\section{General Procedures}

All synthetic manipulations were performed under an atmosphere of dry argon using standard Schlenk-line techniques and/or a Saffron glovebox running with argon unless otherwise stated. All glass apparatus were stored in a drying oven $\left(120^{\circ} \mathrm{C}\right)$ and flamedried in vacuo $\left(10^{-3}\right.$ mbar $)$ before use. Dry solvents were collected from an MBraun solvent system under a nitrogen atmosphere and stored in Schlenk flasks over $4 \AA$ molecular sieves or were dried and purified using common procedures. ${ }^{[10]}$ All chemicals were purchased from Sigma Aldrich and used without further purification. [Li(TMEDA) $\left.]_{2}\left[t \mathrm{BuN}(\mathrm{Te}) \mathrm{P}(\mu-\mathrm{N} t \mathrm{Bu})_{2} \mathrm{P}(\mathrm{Te}) \mathrm{N} t \mathrm{Bu}\right)\right]$ was synthesized according to the literature procedure. ${ }^{[7]}$

\section{Spectroscopic methods}

NMR spectra were recorded using a JEOL DELTA EX 270 or a BRUKER Avance II 400 spectrometer. TMS was used as an internal standard for ${ }^{1} \mathrm{H}$ NMR. $85 \% \mathrm{H}_{3} \mathrm{PO}_{4}$ was used as an external standard for ${ }^{31} \mathrm{P}\left\{{ }^{1} \mathrm{H}\right\}$ NMR spectra. Chemical shifts $(\delta)$ are given in parts per million (ppm) relative to the solvent peaks. ${ }^{[1]}$ Coupling constants $(J)$ are given in Hertz $(\mathrm{Hz})$. Mass spectrometry was performed on a Thermofisher LTQ Orbitrap XL at the EPSRC UK National MS Facility in Swansea. Elemental analysis was performed at the Elemental Analysis Service of the London Metropolitan University (by Mr. S. Boyer).

Preparation of $\left\{(\mathrm{I}) \mathrm{Ag}\left[t \mathrm{Bu}(\mathrm{H}) \mathrm{NP}(\mu \text {-N } t \mathrm{Bu})_{2} \mathrm{P}(\mathrm{Te}) \mathrm{N}(\mathrm{H}) t \mathrm{Bu}\right]_{3}\right\}(2)$ : $\left.[\mathrm{Li}(\mathrm{TMEDA})]_{2}\left[t \mathrm{BuN}(\mathrm{Te}) \mathrm{P}(\mu-\mathrm{N} t \mathrm{Bu})_{2} \mathrm{P}(\mathrm{Te}) \mathrm{N} t \mathrm{Bu}\right)\right] \quad(\mathbf{1}) \quad(200 \mathrm{mg}$, $0.24 \mathrm{mmol}$ ) was suspended in toluene and cooled to $-78^{\circ} \mathrm{C}$. A solution of $\mathrm{AgI}(55 \mathrm{mg}, 0.24 \mathrm{mmol})$ in toluene $(15 \mathrm{~mL})$ was maintained at $-78^{\circ} \mathrm{C}$ and added dropwise over $15 \mathrm{~min}$ by cannula. 
The reaction mixture was stirred for $30 \mathrm{~min}$ before being allowed to warm to RT and stirred for an additional $1 \mathrm{~h}$. The solvent was then removed and the solid residue was dissolved in $n$-hexane, filtered and stored at $-78{ }^{\circ} \mathrm{C}$ overnight. This afforded colourless prism-shaped crystals that were removed by filtration and dried under vacuum. Yield: $14 \%$. Anal. Calcd. for $\mathrm{C}_{48} \mathrm{H}_{114} \mathrm{P}_{6} \mathrm{~N}_{12} \mathrm{AgITe}_{3}$ : C 34.67, H 6.91, N 10.11; found: C 34.79, H 7.03, N 9.95\%.

${ }^{1}$ H NMR $\left(400.30 \mathrm{MHz},\left[\mathrm{D}_{8}\right]\right.$ toluene, $\left.25^{\circ} \mathrm{C}\right): \delta=4.63(3 \mathrm{H}, \mathrm{NH})$, $3.80(3 \mathrm{H}, \mathrm{N} H), 1.63$ (broad, 54H, $2 \times t \mathrm{Bu}), 1.48$ (broad, $27 \mathrm{H}, t \mathrm{Bu})$, 1.30 (broad, 27H, $t \mathrm{Bu}) ;{ }^{31} \mathbf{P}\left\{{ }^{1} \mathbf{H}\right\}$ NMR $\left(109.37 \mathrm{MHz},\left[\mathrm{D}_{8}\right]\right.$ toluene, $\left.25^{\circ} \mathrm{C}\right): \delta[\mathrm{ppm}]=83.0(\mathrm{~s}$, broad $),-46.0\left(\mathrm{~s}\right.$, broad, ${ }^{1} J(\mathrm{P}, \mathrm{Te})=$ $1938.8 \mathrm{~Hz}$ ); HR-MS $\left(\mathrm{ESI}^{+}, \mathrm{m} / z\right), 1537.3856\left[\mathrm{M}^{+}-\mathrm{I}\right]$ (calculated for $\mathrm{C}_{48} \mathrm{H}_{114} \mathrm{~N}_{12} \mathrm{P}_{6} \mathrm{Te}_{3} \mathrm{Ag}$ : $\left.1537.3916\left[M^{+}-\mathrm{I}\right]\right)$.

\section{X-ray Crystallography}

X-ray analysis was performed on a Rigaku Mo MM007 high brilliance generator with a Mercury CCD detector, rotating at $-180(1){ }^{\circ} \mathrm{C}$. Data were collected with Mo- $K_{\alpha}$ radiation $(\lambda=0.71073 \AA)$ and corrected for Lorentz and polarisation effects. The data were collected and processed using CrystalClear (Rigaku). ${ }^{[12]}$ The crystal structure was solved using direct heavyatom Patterson methods ${ }^{[13]}$ and expanded using Fourier techniques. The non-hydrogen atoms were refined anisotropically, hydrogen atoms were refined using the riding model. All calculations were performed using CrystalStructure ${ }^{[14]}$ crystallographic software package and SHELXL-97. ${ }^{[15]}$ The was a large residual electron density peak close to $\mathrm{Te} 4$ which we attribute to absorption effects. Crystallographic data for the structure of $\mathbf{2}$ have been deposited with the Cambridge Crystallographic Centre as supplementary publication no. CCDC 1026309. These data can be obtained free of charge via www.ccdc.cam.ac/uk/conts/retrieving.html (or from the Cambridge Crystallographic Centre, 12, Union Road, Cambridge CB21EZ, UK; fax: (+44)1223-336-033; or deposit@ccdc.cam.ac/uk).

Acknowledgement. The authors are thankful to the EPSRC and NSERC (Canada) for support.

[1] R. A. Zingaro, J. Organometal. Chem. 1963, 1, 200.

[2] N. Kuhn, H. Schumann, G. Wolmershäuser, J. Chem. Soc. Chem. Commun. 1985, 1595-1597.

[3] C. Daniliuc, C. Druckenbrodt, C. G. Hrib, F. Ruthe, A. Blaschette, P. G. Jones, W.-W. du Mont, Chem. Commun. 2007, 2060-2062. Exact structural parameters of $\left[\mathrm{Ag}\left(\mathrm{TePiPr}_{3}\right)_{3}\right]^{+}\left[\left(\mathrm{SO}_{2} \mathrm{CH}_{3}\right)_{2} \mathrm{~N}\right]^{-}$were not provided as the structural refinement was unsatisfactory.

[4] C. C. Druckenbrodt, PhD Thesis, TU Braunschweig, 2000; C. Druckenbrodt, W.-W. du Mont, $34^{\text {th }}$ International Conference on Coordination Chemistry, Edinburgh, UK, poster abstract, $\mathrm{P} 0285$.

[5] T. Chivers, J. S. Ritch, S. D. Robertson, J. Konu, H. M. Tuononen, Acc. Chem. Res. 2010, 43, 1053-1062.

[6] M. C. Copsey, A. Panneerselvam, M. Afzaal, T. Chivers, P. O’Brien, Dalton Trans. 2007, 1528-1538.

[7] G. G. Briand, T. Chivers, M. Parvez, Angew. Chem. 2002 114 (18), 3618-3620, Angew. Chem. Int. Ed. 2002, 41, 3468 3470.

[8] G. G. Briand, T. Chivers, M. Parvez, G. Schatte, Inorg. Chem. 2003, 42, 525-531.
[9] R. J. Bowen, D. Camp, Y. Effend, B. W. Skelton, A. H. White, Aust. J. Chem. 1994, 47, 693-701.

[10] D. D. Perrin, W. L. F. Armarego, Purification of Laboratory Chemicals, Oxford, Butterworth-Heinemann, $6^{\text {th }}$ edn., 2009.

[11] G. R. Fulmer, A. J. M. Miller, N. H. Sherden, H. E. Gottlieb, A. Nudelman, B. M. Stoltz, Organometallics 2010, 29, 21762179.

[12] a) CrystalClear 1.6: Rigaku Corporation, 1999; b) CrystalClear Software User's Guide, Molecular Structure Corporation $^{\odot}, 2000 ;$ c) J. W. Pflugrath, Acta Crystallogr. 1999, D55, 1718-1725.

[13] DIRDIF99: P. T. Beuerskens, G. Admiraal, G. Beuerskens, W. P. Bosman, R. de Gelder, R. Israel, J. M. M. Smits, The DIRDIF-99 program system, Technical Report of the Crystallography Laboratory, University of Nijmegen, The Netherlands, 1999.

[14] CrystalStructure 4.0: Crystal Structure Analysis Package, Rigaku Corporation (2000-2010). Tokyo 196-8666, Japan.

[15] G. M. Sheldrick, Acta Crystallogr. 2008, A64, 112-122.

Received: ((will be filled in by the editorial staff)) Published online: ((will be filled in by the editorial staff)) 


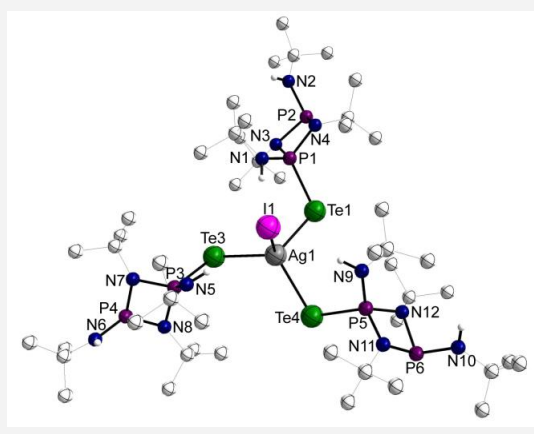

A.Nordheider, A. M. Z. Slawin, J. D. Woollins, T. Chivers* ${ }^{[a]}$

Page No. - Page No.

A Silver(I) Iodide Complex of a Tellurophosphorane 